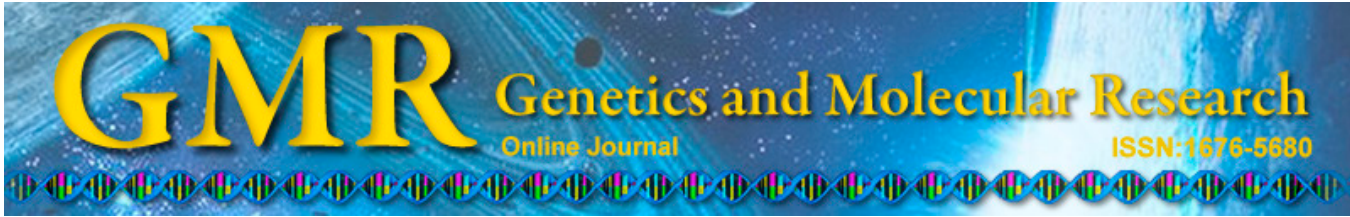

\title{
Identification of an SCAR marker related to female phenotype in Idesia polycarpa Maxim.
}

S.H. Wang, Y. Li, Z.Q. Li, L. Chang and L. Li

College of Forestry, Northwest A\&F University, Yangling, Shaanxi, China

Corresponding author: Z.Q. Li

E-mail: lizhouqi@nwsuaf.edu.cn

Genet. Mol. Res. 14 (1): 2015-2022 (2015)

Received January 23, 2014

Accepted June 30, 2014

Published March 20, 2015

DOI http://dx.doi.org/10.4238/2015.March.20.11

\begin{abstract}
Idesia polycarpa Maxim. is a dioecious species. Because of the lack of morphological and cytological methods available for identifying its sex during the long juvenile stage, the application of molecular markers in sex identification may facilitate sex determination in the seedling stage. The objective of this study was to use sequencerelated amplified polymorphism to identify sex-linked markers in $I$. polycarpa and convert these markers into sequence-characterized amplified region markers, which are much easier to identify. A total of 342 primer combinations were screened and 2770 bands were examined. Only me14/em8 could amplify a specific fragment (210 base pairs) in all female but none in male plants. We analyzed this fragment using GenBank and found that the sequence similarity was $80 \%$ to the Populus trichocarpa clone POP006-H09 (sequence ID: gb|AC212923.1|) and that of the deduced amino acid sequence was $73 \%$ to the integrase of Mendicago truncatula (sequence ID: gb|ABD28291.1|) and 71\% to the predicted retrotransposon integrase-like protein 1-like in Cicer arietinum (sequence ID: ref|XP 004515460.1|) (NCBI database through December 17, 2013). This fragment was converted into a stable and simple sequencecharacterized amplified region marker approximately 200 base pairs in length. This marker can be utilized for early sexual identification in $I$. polycarpa, which will facilitate future breeding programs.
\end{abstract}

Key words: Dioecious; Idesia polycarpa Maxim.; SCAR; Transposition; Sex determination; SRAP 


\section{INTRODUCTION}

Idesia polycarpa Maxim. is a dioecious tree of the Flacourtiaceae family. This tree is native to some Asian countries, including Korea, Japan, and China (Kim et al., 2005). In China, I. polycarpa is widely cultivated in the provinces to the south of Qinling Mountain and Huaihe River. Additionally, because of its adaptability and beautiful appearance, I. polycarpa is an ideal plant for gardeners in northern China. The fruit of this plant has also been used to prepare edible oil (Yang et al., 2009), which contains a variety of compounds such as idesolide, which may be useful in combating obesity (Hwang et al., 2012). As an energy plant, the female trees are more valuable than male trees for practical application. The tree flower from May through June, depending on the temperature, when it is possible to easily determine the sex of the tree. However, the reproductive maturity of seedlings takes 5 or 6 years, making it difficult to distinguish the male and female plants. There have been no previous studies examining the sex chromosomes of male and female individuals. Thus, predicting the sex of an I. polycarpa plant before the flower buds mature is difficult. A method for determining the gender of this plant during the seedling stage would facilitate selection and breeding.

Although $10 \%$ of flowering plants produce unisexual flowers, relatively little information is available regarding the genetic basis of sex determination. Many studies focused on sex determination in plants (Adam et al., 2011), but most plant species do not have distinct sex chromosomes. Therefore, cytological methods cannot be used to identify sex in most dioecious plants. Many dioecious plants have been successfully used for studying sexual determination, such as Asparagus officinalis L. (Jiang and Sink, 1997), Eucommia ulmoides Oliv. (Wang et al., 2011), and Buchloe dactyloides (Zhou et al., 2011), among others.

In recent years, various molecular marker systems have been developed and used for the study of sex identification in plants. These methods include restriction fragment length polymorphism (RFLP) (Nelson et al., 2005), random amplified polymorphic DNA (RAPD) (Samantaray et al., 2010), amplified fragment length polymorphism (AFLP) (Witkowicz et al., 2003), and simple sequence repeats (SSR) (Markussen et al., 2007; Pakull et al., 2011). RFLP is time consuming and labor intensive. Although AFLP provides a high multiplexing ratio, high DNA quality is required and this method is complex. SSR is one of the most widely used marker systems because of its extensive dispersion around the genome and because it produces co-dominant markers, but it is expensive to develop. Although, RAPD is the most widely used molecular marker for sex identification, its low reproducibility limits its effectiveness (Zhou et al., 2011). These techniques generate relatively complex patterns for identification purposes and make the analysis of DNA fragments tedious and time consuming. Therefore, developing efficient methods for easy and accurate identification in routine procedures is imperative. The sequence characterized amplified region (SCAR) was first derived from RAPD fragments (Paran and Michelmore, 1993). It has been recently developed for various identification applications (Naqvi and Chattoo, 1996; Gunter et al., 2003). However, few RAPD markers can be transformed into SCARs (Vidal et al., 2000).

In contrast, the sequence related amplified polymorphism (SRAP) marker system was first described by Li and Quiros (2001). It is based on 2-primer amplification. The forward primers amplify exons to open reading frame regions, while the reverse primers target promoter and intron regions. Compared with other systems, SRAP has several advantages: it is easier than RFLP, simpler than AFLP, less expensive than SSR, and more stable than RAPD. Most importantly, it allows for the easy isolation of DNA fragments for sequencing. Thus, by 
cloning the amplified bands, sequencing the ends, and then using the sequences to generate extended oligomer primers, SRAPs can be converted into stable and reliable markers. However, there is little information regarding the use of SRAP for sex identification and only in a few plant species (Zhou et al., 2011).

Thus, the goal of this study was to develop a reproducible, convenient, and reliable sex marker for I. polycarpa Maxim. Here, we describe a female-specific SRAP marker and its conversion into a SCAR marker. According to the sequence analysis of the SRAP marker, we predicted the development of sex in I. polycarpa plants.

\section{MATERIAL AND METHODS}

\section{Plant materials and DNA extraction}

All trees studied were distributed in 5 different regions in Shannxi Province (Table 1). We located 11 male and 16 female trees in Hanzhong. In Ankang, there were 10 male and 9 female trees. In the nursery of Northwest A\&F University, there was 1 male and 5 female trees.

Genomic DNA was isolated according to the method described by Porebski et al. (1997) with minor modifications. Young leaf tissues $(0.5 \mathrm{~g})$ were ground in liquid nitrogen and $1 \mathrm{~mL} 2 \mathrm{X}$ cetyltriethylammnonium bromide extraction buffer. The tube was incubated for $45 \mathrm{~min}$ at $65^{\circ} \mathrm{C}$ and then centrifuged at $12,000 \mathrm{rpm}$ for $10 \mathrm{~min}$. To the supernatant, $1 \mathrm{~mL}$ chloroform/isoamyl alcohol (24:1) was added and the sample was centrifuged at 12,000 rpm for $10 \mathrm{~min}$. The supernatant was transferred and one-tenth of the aqueous layer volume of 3 $\mathrm{M}$ sodium acetate and an equal volume chilled ethanol were added. The DNA precipitate was washed twice with $75 \%(\mathrm{v} / \mathrm{v})$ ethanol and dissolved in $200 \mu \mathrm{L}$ ultrapure water. The DNA was quantified on a $1.0 \%$ agarose gel by visual comparison with known quantities of DNA ladder (CWBio, CoWin Bioscience Co., Ltd. Beijing, China). The DNA concentration was determined by an UV spectrophotometer. The DNA was diluted to a final concentration of $200 \mathrm{ng} /$ $\mu \mathrm{L}$. All genomic DNA was stored at $-20^{\circ} \mathrm{C}$ until use.

DNA samples from 30 females and 22 males were mixed in equal volumes to construct 2 DNA pools.

Table 1. Geographic location and sample size of male and female trees.

\begin{tabular}{|c|c|c|c|c|c|}
\hline \multirow[t]{2}{*}{ Location } & \multicolumn{2}{|c|}{ Sample size } & \multicolumn{3}{|c|}{ Approximate geographic location } \\
\hline & Male & Female & Latitude (N) & Longitude (E) & Altitude (m) \\
\hline Ningqiang county, Hanzhong & 2 & 4 & $32^{\circ} 37^{\prime}-33^{\circ} 12^{\prime}$ & $105^{\circ} 21^{\prime}-106^{\circ} 35^{\prime}$ & $620-1000$ \\
\hline Shujiaba county, Hanzhong & 9 & 12 & $32^{\circ} 50^{\prime}-32^{\circ} 55^{\prime}$ & $105^{\circ} 25^{\prime}-106^{\circ} 07^{\prime}$ & $1000-1800$ \\
\hline Langao county, Ankang & 9 & 9 & $32^{\circ} 17^{\prime}-32^{\circ} 30^{\prime}$ & $108^{\circ} 54^{\prime}$ & $1020-2100$ \\
\hline Ziyang county, Ankang & 1 & & $32^{\circ} 31^{\prime}$ & $108^{\circ} 32^{\prime}$ & 477 \\
\hline Nursery of Northwest A\&F & 1 & 5 & $34^{\circ} 15^{\prime}$ & $108^{\circ} 39^{\prime}$ & 563 \\
\hline University, Yangling & & & & & \\
\hline
\end{tabular}

\section{SRAP analysis}

SRAP analysis was carried out according to the method described by Li and Quiros (2001), Ferriol et al. (2003), and Li et al. (2003). A total of 342 combinations of 18 forward primers and 19 reverse primers (Life Technologies, Carlsbad, CA, USA) were used (Table 2). 
Each amplification reaction was carried out in a $25-\mu \mathrm{L}$ volume that included $1 \mu \mathrm{L} 200 \mathrm{ng} / \mu \mathrm{L}$ genomic DNA, $0.3 \mu \mathrm{M}$ (each) forward and reverse primer, $2.5 \mathrm{U}$ Taq polymerase, $250 \mathrm{mM}$ dNTPs, $1.5 \mathrm{mM} \mathrm{MgCl}$, and $1 \mathrm{X}$ polymerase chain reaction (PCR) buffer. The reaction was completed using the following cycle parameters: denaturation at $94^{\circ} \mathrm{C}$ for $5 \mathrm{~min} ; 5$ cycles of 1 min at $94^{\circ} \mathrm{C}, 1 \mathrm{~min}$ at $35^{\circ} \mathrm{C}$, and $1 \mathrm{~min}$ at $72^{\circ} \mathrm{C} ; 35$ cycles of $1 \mathrm{~min}$ at $94^{\circ} \mathrm{C}, 1 \mathrm{~min}$ at $50^{\circ} \mathrm{C}$, and $1 \mathrm{~min}$ at $72^{\circ} \mathrm{C}$; and an annealing temperature at $72^{\circ} \mathrm{C}$ for $8 \mathrm{~min}$. PCR products were analyzed by electrophoresis on $6 \%$ polyacrylamide gel using a vertical-gel apparatus (LiuYi, Beijing, China) in $1 \mathrm{X}$ Tris/boric acid/EDTA buffer at $250 \mathrm{~V}$ constant current for $2.5 \mathrm{~h}$. Amplified DNA fragments were detected using the silver-straining method.

Table 2. Primer sequences of polymorphic SRAP markers used in this study.

\begin{tabular}{|c|c|c|c|}
\hline \multicolumn{2}{|r|}{ Forward primers $\left(5^{\prime} \rightarrow 3^{\prime}\right)$} & \multicolumn{2}{|r|}{ Reverse primers $\left(5^{\prime} \rightarrow 3^{\prime}\right)$} \\
\hline me1 & TGAGTCCAAACCGGATA & $\mathrm{em} 1$ & GACTGCGTACGAATTAAT \\
\hline me2 & TGAGTCCAAACCGGAGC & $\mathrm{em} 2$ & GACTGCGTACGAATTTGC \\
\hline me3 & TGAGTCCAAACCGGAAT & em3 & GACTGCGTACGAATTGAC \\
\hline me4 & TGAGTCCAAACCGGACC & $\mathrm{em} 4$ & GACTGCGTACGAATTTGA \\
\hline me5 & TGAGTCCAAACCGGAAG & em5 & GACTGCGTACGAATTAAC \\
\hline me6 & TGAGTCCAAACCGGTAA & em6 & GACTGCGTACGAATTGCA \\
\hline me7 & TGAGTCCAAACCGGTCC & em7 & GACTGCGTACGAATTCAA \\
\hline me8 & TGAGTCCAAACCGGTGC & em8 & GACTGCGTACGAATTCTG \\
\hline me9 & TGAGTCCAAACCGGACA & em9 & GACTGCGTACGAATTCAC \\
\hline me10 & TGAGTCCAAACCGGACG & em10 & GACTGCGTACGAATTCAT \\
\hline me11 & TGAGTCCAAACCGGACT & em11 & GACTGCGTACGAATTCTA \\
\hline me12 & TGAGTCCAAACCGGAAC & em12 & GACTGCGTACGAATTGTC \\
\hline me13 & TGAGTCCAAACCGGATG & $\mathrm{em} 13$ & GACTGCGTACGAATTCTC \\
\hline me14 & TGAGTCCAAACCGGAGT & em14 & GACTGCGTACGAATTCAG \\
\hline me15 & TGAGTCCAAACCGGTAG & em 15 & GACTGCGTACGAATTGAT \\
\hline me16 & TGAGTCCAAACCGGTTG & em16 & GACTGCGTACGAATTGAG \\
\hline me17 & TGAGTCCAAACCGGTGT & em17 & GACTGCGTACGAATTGCC \\
\hline \multirow[t]{2}{*}{ me18 } & TGAGTCCAAACCGGCAT & $\mathrm{em} 18$ & GACTGCGTACGAATTTCA \\
\hline & & em19 & GACTGCGTACGAATTACT \\
\hline
\end{tabular}

\section{SCAR marker development}

The fragment of sex-specific was excised from polyacrylamide gel electrophoresis and extracted using the Long Range Gel Extraction Kit (CWBio). A total of $1 \mu \mathrm{L}$ extraction product was used as a template in the $25-\mu \mathrm{L}$ PCR mix (as used for SRAP amplification, above) which contained the same primer combination. PCR products were separated by electrophoresis on a $2.0 \%$ agarose gel. The selected fragment was excised from the gel and purified using the UNIQ-10 EZ Spin Column DNA Gel Extraction Kit (Sangon Biotech Co., Ltd., Shanghai, China). The DNA band was ligated into the pUC-T cloning vector using cloning kit (CWBio). Recombinant plasmids were transformed into Escherichia coli strain (DH5 $\alpha$ ) using the heat shock method. The cloned DNA fragment was sequenced by Life Technologies Inc. The sequence was analyzed using NCBI BLAST algorithms (http://www. ncbi.nlm.nih.gov).

SCAR primers were designed according to the sequence of the cloned SRAP fragment. The annealing temperature of these primers was measured using the software Oligo 7.0. The SCAR reaction was carried out in a $25 \mu \mathrm{L}$ mixture using the following cycling parameters: 1 cycle for $4 \mathrm{~min}$ at $94^{\circ} \mathrm{C} ; 30$ cycles for $1 \mathrm{~min}$ at $94^{\circ} \mathrm{C}, 1 \mathrm{~min}$ at the annealing temperature, and $2 \mathrm{~min}$ at $72^{\circ} \mathrm{C}$; followed by final extension at $72^{\circ} \mathrm{C}$ for $7 \mathrm{~min}$. The PCR products of 
each sample were examined on a $2.0 \%$ agarose gel to determine whether the SCAR primers had been converted successfully.

\section{RESULTS}

In this study, 342 primer combinations were used to identify the sex-specific SRAP marker in the 2 DNA pools. Of these, 308 combinations generated a total of approximately 2770 fragments, ranging from 50-2000 base pairs (bp), and 76 pairs of potential primers produced 109 DNA fragments that differed between the 2 DNA pools. Only 1 pair of primers amplified a stable and specific fragment in all female samples, but none in the males when each of the 30 female and 22 male individuals was tested (Figure 1). The sex-specific fragment (210 $\mathrm{bp}$ ) in the female pool was amplified by primers me14 and em8. This result was tested at least 3 times using the same procedure and the amplification pattern was found to be consistent.

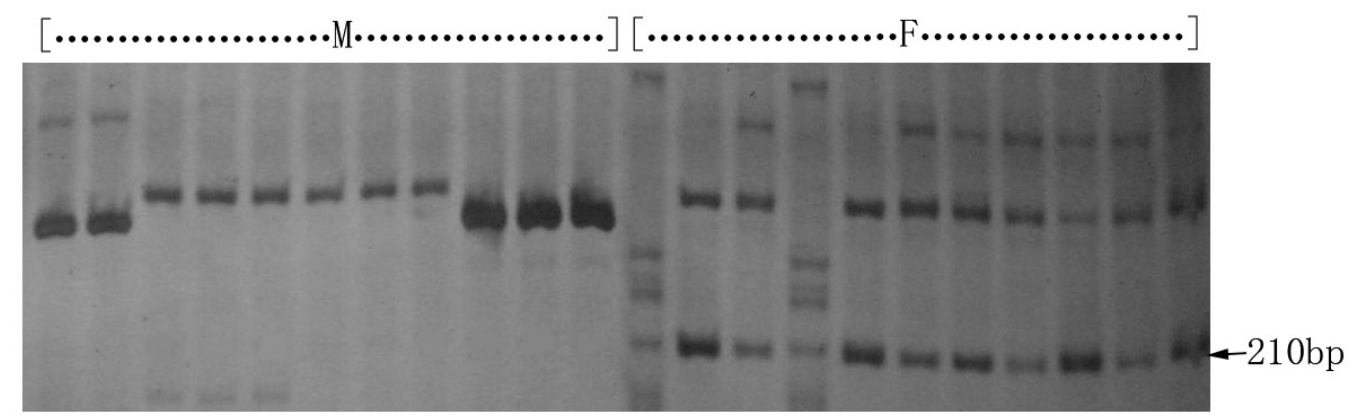

Figure 1. SRAP band patterns from DNA extracted from 11 male $(\mathbf{M})$ and 11 female $(\mathbf{F})$ individuals using primer combination me14/em8. The specific fragment ( $210 \mathrm{bp})$ is indicated by an arrow.

The sequence of the cloned female-specific fragment was determined (Figure 2). The sequence was evaluated using GenBank and the sequence similarity was $85 \%$ to the Populus trichocarpa clone POP021-E24 (sequence ID: gb|AC216545.1|). Additionally, pairwise alignment of the deduced amino acid sequence of this fragment revealed that the sequence similarity was $73 \%$ to the integrase of Medicago truncatula (sequence ID: gb|ABD28291.1|) and 71\% to the predicted retrotransposon integrase-like protein 1-like in Cicer arietinum (sequence ID: ref|XP 004515460.1|) (NCBI database through December 17, 2013).

The primers TZS1 and TZS2 were designed based on the sequences (Figure 2). The optimized annealing temperature of the SCAR primers was $60^{\circ} \mathrm{C}$. At this annealing tempera-

\section{TGAGTCCAAA CCGGAGTAAA TGGGTACCAA ACTATGAGGG TCCTTATATA TZS1 \\ GTGAAGAAA CTTTTTCAAT AGAAGCCCTA ATATTGTTTA GCATGGATGG AGAAGATTTA GCCAGACCTG TGAATTCTGA TTCTATGAAG AAATACATGT ATGATGAGGT GTTTCTTAGT CGATTGGTT GTGGTTAAATC CCCTGAATTG}

GTACGCAGTC

Figure 2. Sequence of the female-specific marker (210 bp). The boldfaced underlined nucleotides define the forward and reverse SCAR primers (TZS1 and TZS2). 
ture, a SCAR marker was obtained ( $200 \mathrm{bp})$. The agarose gel in Figure 3 shows that the marker was observed in all the female individuals, but in none of the male plants. Thus, the female-specific SRAP marker was successfully converted into a SCAR marker.

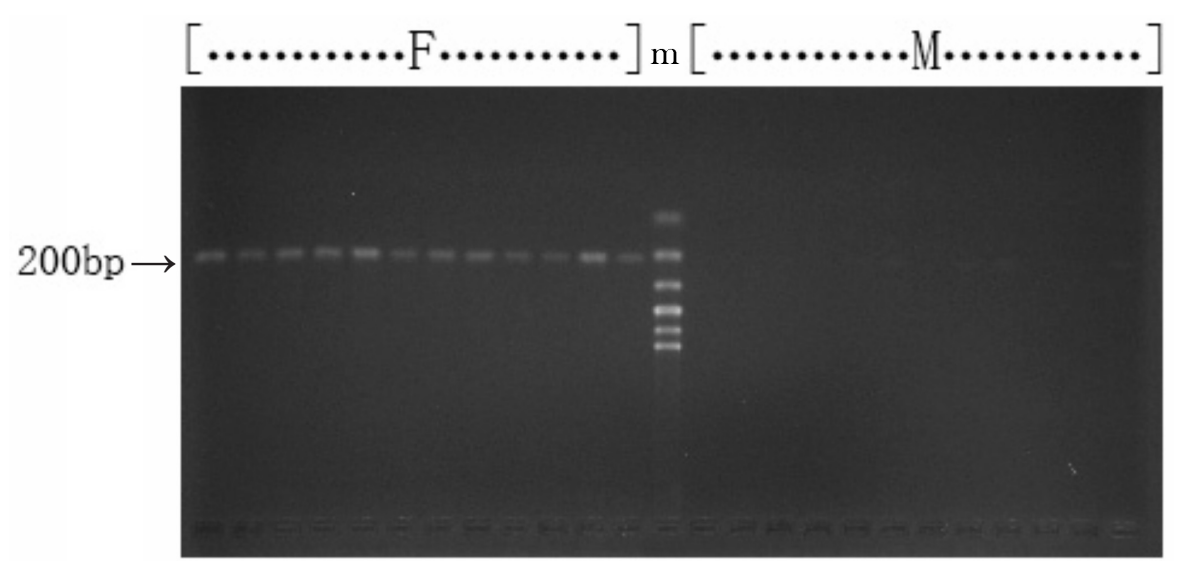

Figure 3. SCAR marker linked to sex in Idesia polycarpa Maxim. analyzed using the primer combination TZS1 and TZS2 of individual plants obtained from the female plant (arrow). A band approximately $200 \mathrm{bp}$ was observed in the females (F) but not in the males (M). A 100-bp DNA ladder is shown in lane $m$.

\section{DISCUSSION}

Currently, there is no reliable method for identifying the sex of I. polycarpa seedlings in early stages. In this study, we used the SRAP marker system to identify sex-specific fragments. Zhou et al. (2011) previously found a female SRAP marker ( $240 \mathrm{bp})$ in B. dactyloides. Because it is much easier to sequence and convert an SRAP into a SCAR marker, these markers can be used as new research tools for sex identification (Vidal et al., 2000). SCAR marker can be easily amplified by PCR and are easily detected on agarose gel electrophoresis.

The development of unisexual flowers has long been used as a model system for understanding the mechanism of plant sex determination (Bai and Xu, 2012). Several researchers have attempted to determine the molecular mechanisms of sex determination in dioecious plants. However, most plant species do not have distinct sex chromosomes. Therefore, cytological methods cannot be used to identify sex in most dioecious plants; however, molecular markers show potential for this purpose. According to Chuck (2010), the development of unisexual flowers appears to have occurred several times independently, suggesting that plants may have evolved different sex-determination mechanisms. Martin et al. (2009) showed that the insertion of a transposon (and consequent DNA methylation changes) in the promoter of a zinc finger transcription factor gene, CmWIP1 resulted in the transition from male to female flowers in gynoecious lines of melon. In this study, we found a female-specific SRAP marker, which showed homology to some database sequences in BLAST and BLASTn searches, including $73 \%$ to the integrase of $M$. truncatula and $71 \%$ to the predicted retrotransposon integrase-like protein 1-like in C. arietinum. However, the specific fragment we identified was short, which may have increased the similarity with other DNA or protein sequences. However, these results may also indicate that a transposable mobile element is responsible for sex development in I. polycarpa. In fact, according to the farmers living in Qinling Mountain, 
some I. polycarpa male trees (already attaining reproductive maturity) produce a few seeds in autumn. However, many other different genotypes of female and male individuals in dioecious plants limit the accurate detection of DNA methylation sites and expression levels. Thus, further studies should be conducted to determine whether this phenomenon exists and it is related to transposon behavior.

In this study, we attempted to identify 30 male and 30 female trees, but only identified 30 females and only 22 males. The sex ratio of I. polycarpa in the 5 locations in our study was female-biased. Dioecious plant species make up approximately $4 \%$ of all plant species (Ainsworth, 2000), and often show variation in the local proportion of male-to-female plants. Sex ratios are genetically important to plant populations. Population sex ratio of I. polycarpa is of direct interest to humans, as the production of fruit is a primary goal. Thus, further studies should be conducted to determine the sex ratio of other I. polycarpa populations and the mechanisms affecting these ratios.

This is the first study to describe the transformation of a specific SRAP marker into reliable SCAR marker for use in sex identification of I. polycarpa. However, we did not analyze the accuracy of the SCAR marker in a larger population. Our SCAR marker may be linked with the loci of the gender we are interested in studying. Subsequent studies will be conducted to test the accuracy of the SCAR marker in a larger population.

\section{ACKNOWLEDGMENTS}

The authors wish to thank Ankang Forestry Bureau of Shannxi Province and Mr. Kang Kai, Mr. Yi-Jun Yang, Ms. Gui-Ying Xiang, and Dr. Mei-Ying Liu for the plant material. We also thank all colleagues in our laboratory for constructive discussion, technical support, and critical of the manuscript.

\section{REFERENCES}

Adam H, Collin M, Richaud F, Beulé T, et al. (2011). Environment regulation of sex determination in oil palm: current knowledge and insight from other species. Ann. Bot. 108: 1529-1537.

Ainsworth C (2000). Boys and girls come out to play: the molecular biology of dioecious plants. Ann. Bot. 86: 211-221.

Bai SN and Xu ZH (2012). Bird-nest puzzle: can the study of unisexual flowers such as cucumber solve the problem of plant sex determination? Protoplasma 249 (Suppl 2): S112-S123.

Chuck G (2010). Molecular mechanisms of sex determination in monoecious and dioecious plants. Adv. Bot. Res. 54: 54-83.

Ferriol M, Picó B and Nuez F (2003). Genetic diversity of a germplasm collection of Cucurbita pepo using SRAP and AFLP markers. Theor. Appl. Genet. 107: 271-282.

Gunter LE, Roberts GT, Lee K, Larimer FW, et al. (2003). The development of two flanking SCAR markers linked to a sex determination locus in Salix viminalis L. J. Hered. 94: 185-189.

Hwang JH, Moon SA, Lee CH, Byun MR, et al. (2012). Idesolide inhibits the adipogenic differentiation of mesenchymal cells through the suppression of nitric oxide production. Eur. J. Pharmacol 685: 218-223.

Jiang CX and Sink KC (1997). RAPD and SCAR markers linked to the sex expression locus $M$ in asparagus. Euphytica 94: 329-333.

Kim SH, Sung SH, Choi SY, Chung YK, et al. (2005). Idesolide: A new spiro compound from Idesia polycarpa. Org. Lett. 7: 3275-3277.

Li G and Quiros CF (2001). Sequence-related amplified polymorphism (SRAP), a new marker system based on a simple PCR reaction: its application to mapping and gene tagging in Brassica. Theor. Appl. Genet. 103: 455-461.

Li G, Gao M, Yang B and Quiros CF (2003). Gene for gene alignment between the Brassica and Arabidopsis genomes by direct transcriptome mapping. Theor. Appl. Genet. 107: 168-180.

Markussen T, Pakull B and Fladung M (2007). Positioning of sex-correlated markers for Populus in a AFLP- and SSRmarker based genetic map of Populus tremula x tremuloides. Silvae Genetica 56: 3-4. 
Martin A, Troadec C, Boualem A, Rajab M, et al. (2009). A transposon-induced epigenetic change leads to sex determination in melon. Nature 461: 1135-1138.

Naqvi NI and Chattoo BB (1996). Development of a sequence characterized amplified region (SCAR) based indirect selection method for a dominant blast-resistance gene in rice. Genome 39: 26-30.

Nelson MN, Nixon J and Lydiate DJ (2005). Genome-wide analysis of the frequency and distribution of crossovers at male and female meiosis in Sinapis alba L. (white mustard). Theor. Appl. Genet. 111: 31-43.

Pakull B, Groppe K, Mecucci F, Gaudet M, et al. (2011). Genetic mapping of linkage group XIX and identification of sexlinked SSR markers in a Populus tremula x Populus tremuloides cross. Can. J. For. Res. 41: 245-253.

Paran I and Michelmore RW (1993). Development of reliable PCR-based markers linked to downy mildew resistance genes in lettuce. Theor. Appl. Genet. 85: 985-993.

Porebski S, Bailey LG and Baum BR (1997). Modification of a CTAB DNA extraction protocol for plants containing high polysaccharide and polyphenol components. Plant Mol. Biol. Rep. 15: 8-15.

Samantaray S, Geetha KA, Hidayath KP and Maiti S (2010). Identification of RAPD markers linked to sex determination in guggal [Commiphora wightii (Arnott.)] Bhandari. Plant Biotechnol. Rep. 4: 95-99.

Vidal JR, Delavault P, Coarer M and Defontaine A (2000). Design of grapevine (Vitis vinifera L.) cultivar-specific SCAR primers for PCR fingerprinting. Theor. Appl. Genet. 101: 1194-1201.

Witkowicz J, Urbanczyk-Wochniak E and Przybecki Z (2003). AFLP marker polymorphism in cucumber (Cucumis sativus L.) near isogenic lines differing in sex expression. Cell Mol. Biol. Lett. 8: 375-381.

Wang DW, Li Y and Li ZQ (2011). Identification of a male-specific amplified fragment length polymorphism (AFLP) and a sequence characterized amplified region (SCAR) marker in Eucommia ulmoides Oliv. Int. J. Mol. Sci. 12: 857-864.

Yang FX, Su YQ, Li XH, Zhang Q, et al. (2009). Preparation of biodiesel from Idesia polycarpa var. vestita fruit oil. Ind. Crops Prod. 29: 622-628.

Zhou YJ, Wang XG and Zhang XQ (2011). Development and application of a SRAP marker for the identification of sex in Buchloe dactvloides. Euphytica 181: 261-266. 